\title{
Comparison of hyperfibrinolysis in trauma and non-trauma patients
}

\author{
T Madelaine $^{1 *}$, G Marcotte ${ }^{1}$, L Rugeri ${ }^{2}$, J-X Taverna ${ }^{3}$, D Massignon ${ }^{4}$, B Floccard ${ }^{1}$, T Rimmelé ${ }^{1}$, J-S David ${ }^{1,3}$ \\ From ESICM LIVES 2015 \\ Berlin, Germany. 3-7 October 2015
}

\section{Introduction}

Hyperfibrinolysis (HF) is a major issue of traumainduced coagulopathy but has also been described in many other medical or surgical settings such as cardiopulmonary surgery, gastro-intestinal bleeding, liver transplantation and post-partum hemorrhage.

\section{Objectives}

The aim of this study was to describe the HF in a cohort of patients experiencing severe bleeding from trauma and non-trauma source and to highlight the differences between both groups.

\section{Methods}

We conducted an observational, retrospective study in two academic trauma centers from a French university institution. All patients diagnosed with HF on rotational thromboelastometry $\left(\right.$ ROTEM $^{\circledR}$ ) between 2010 and 2014 were included. Demographic and clinical parameters, standard laboratory and ROTEM ${ }^{\circledR}$ results were collected. HF diagnosis was established when the $60 \mathrm{~min}$ ute clot lysis index $\left(\mathrm{CLI}_{60}\right)$ was below $85 \%$ of the maximum clot firmness. HF was classified as fulminant HF (immediate breakdown of the clot within 30 minutes), intermediate HF (breakdown of the clot between 30 and 60 minutes) and late HF (complete clot lysis after more than 60 minutes). Data are expressed as $\mathrm{n}(\%)$ and median [interquartile range].

\section{Results}

Sixty-four patients were included (39 trauma and 25 non trauma). Overall mortality was $64 \%$ (95\% confidence interval $[\mathrm{CI}], 52$ to 76 ). Median ISS for trauma patients was 49 (95\% CI, 42 to 55). Patients severity

${ }^{1}$ Hospices Civils de Lyon, Department of Anesthesiology and Intensive Care, Groupement Hospitalier Edouard Herriot, Lyon, France

Full list of author information is available at the end of the article assessed with SAPS II was not different between groups (median [IQR] for trauma 76 [23] vs. non trauma 57 [47]; $\mathrm{p}=0.36)$ whereas 28 day survival was greater in non-trauma patients (53\% [95\% CI, 31 to 73 ] vs. $26 \%$ [95\% CI, 11 to 40]; $\mathrm{p}=0.03$ ) (Figure 1). More fulminant HF were observed in the trauma group $(p<0.01)$. Survival was also different according to the type of $\mathrm{HF}$ and was inferior in the fulminant group (14\% [95\% CI, 0 to 27] vs. intermediate: $25 \%$ [ $95 \%$ CI, 0 to 54 ] vs. late: $70 \%$ [95\% CI, 49 to 90]; $\mathrm{p}<0.001$ ). During the study period, HF incidence in trauma patients decreased from 2.9 for 100 patients-years (2011) to 1.6 (2012) and 0.4 (2013) with no significant variation in trauma severity (ISS: 21 [95\% CI, 20 to 23] (2011), 19 [95\% CI, 18 to 20] (2012) and 20 [95\% CI, 19 to 21] (2013); p = 0.30).

\section{Conclusions}

Fulminant HF is more frequent in trauma patients and is associated with an increased mortality. The decreasing

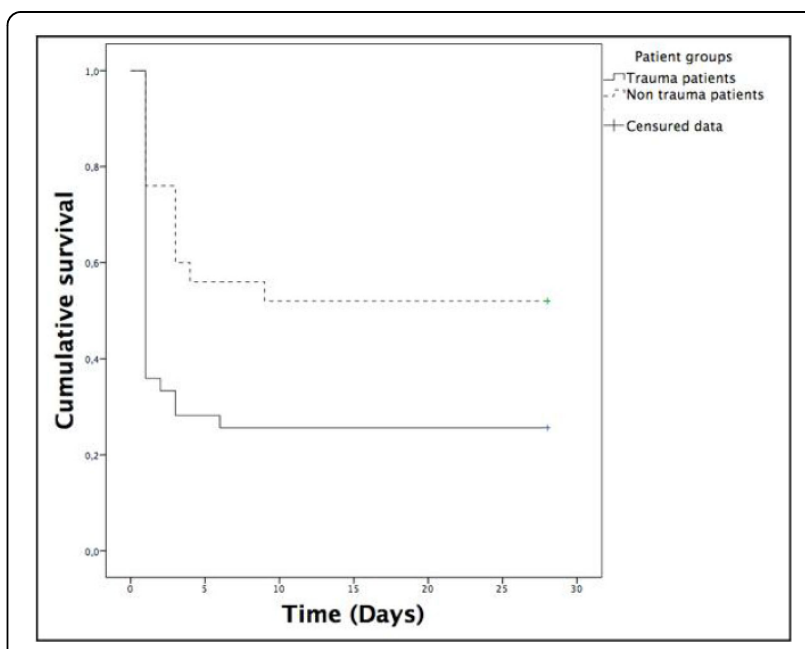

Figure 1 Twenty-eight day survival of trauma and non trauma. 
incidence of HF observed during the study period might be due to the systematic prehospital administration of tranexamic acid in trauma patients since 2011 in our city area.

\section{Authors' details}

${ }^{1}$ Hospices Civils de Lyon, Department of Anesthesiology and Intensive Care, Groupement Hospitalier Edouard Herriot, Lyon, France. ${ }^{2}$ Hospices Civils de Lyon, Department of Hemostasis, Hôpital Louis Pradel, Lyon, France. ${ }^{3}$ Hospices Civils de Lyon, Department of Anesthesiology and Intensive Care, Groupement Hospitalier Lyon-Sud, Lyon, France. ${ }^{4}$ Hospices Civils de Lyon, Department of Hemostasis, Groupement Hospitalier Lyon-Sud, Lyon, France.

Published: 1 October 2015

doi:10.1186/2197-425X-3-S1-A851

Cite this article as: Madelaine et al:: Comparison of hyperfibrinolysis in trauma and non-trauma patients. Intensive Care Medicine Experimental 2015 3(Suppl 1):A851.

\section{Submit your manuscript to a SpringerOpen ${ }^{\circ}$ journal and benefit from:}

- Convenient online submission

- Rigorous peer review

- Immediate publication on acceptance

- Open access: articles freely available online

- High visibility within the field

- Retaining the copyright to your article

Submit your next manuscript at $>$ springeropen.com 